\title{
Peertechz
}

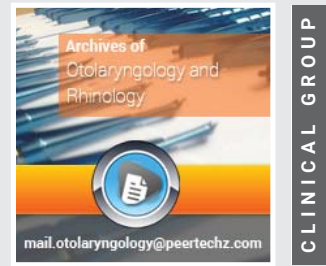

\section{Computed Tomography (CT) contributes in the functional outcome of Endoscopic} Septopasty

\author{
Islam MA ${ }^{1 *}$, Mamoon $\mathrm{TB}^{2}$, Miki FU ${ }^{3}$, Chowdhury $\mathrm{NH}^{4}$, Khan \\ $\mathrm{SR}^{5}$, Rahman $\mathrm{ASL}^{6}$, Miah $\mathrm{MAS}^{7}$ and Mohammad $\mathrm{T}^{8}$
}

'MBBS, FCPS, FICS, FRCS (Glasgow), Professor and Head, Otolaryngology-Head \& Neck Surgery, Bangladesh Medical College Hospital, Bangladesh

${ }^{2}$ MBBS, Assistant Registrar, ENT, Bangladesh Medical College Hospital, Bangladesh ${ }^{3}$ MBBS, DLO Consultant ENT, Bangladesh Medical College Hospital, Bangladesh ${ }^{4}$ MBBS, FCPS, Assistant Professor, ENT, Bangladesh Medical College Hospital, Bangladesh ${ }^{5} \mathrm{MBBS}$, Assistant registrar, ENT, National Institute of ENT, Bangladesh ${ }^{6}$ MBBS, MCPS, DLO, MRCPS (Glasgow), Resident Surgeon, Bangladesh Medical College Hospital, Bangladesh

${ }^{7}$ Director, Bangladesh Medical College Hospital, Bangladesh

${ }^{8}$ MBBS, FCPS, Assistant Registrar ENT, Bangladesh Medical College Hospital, Bangladesh

Received: 06 August, 2020

Accepted: 14 August, 2020

Published: 17 August, 2020

*Corresponding author: Md. Ashraful Islam MBBS, FCPS, FICS, FRCS (Glasgow), Professor and Head, Professor and Head, Otolaryngology-Head \& Neck Surgery, Bangladesh Medical College Hospital, Eastern Baily, Flat 301, 146 New Baily Road, Dhaka 1217, Bangladesh, Tel: +8801711527954; Fax: 880-2 9125655; E-mail: ashrafis123@yahoo.com Keywords: Contribution of CT; Endoscopic septoplasty; Functional outcome

https://www.peertechz.com

Check for updates

\section{Abstract \\ Background and objective: Septoplasty is the common surgical procedure performed in nasal septal deviation. Nasal obstruction is the most frequent presentation to the otolaryngologist all over the world with septal deviation. Patients usually presented with headache, epistaxis, ophthalmological, otological, upper and lower respiratory tract infections; and many more. Physical examination, Anterior Rhinoscopy (AR) and Nasal Endoscopy (NE) are considered the gold standard tools to detect septal deviation. Computed Tomography (CT) contributes in the evaluation of the nasal septum, anatomical variants and unveils the associated sinonasal diseases. This study aimed to assess the contribution of CT in endoscopic septoplasty for long term benefits to the patients.}

Patients and methods: 188 patients of nasal septal deviation were selected from 2015 to 2019 in the Bangladesh Medical and Popular Medical College Specialized Hospital. Age ranged in between 10 year to 70 year of age. CT scanning in both coronal, axial and sagittal sections had been done in all patients after proper history taking, physical examination, anterior rhinoscopy and nasal endoscopy. Endoscopic septoplasty alone and/or other ancillary procedures were performed in all 188 patients under general anesthesia.

Results: Among 188 patients, male was $126(67 \%)$ and female was $62(33 \%)$ with a ratio 2:1. Maximum 63 (34\%) reported in 31 to 40 year and 54 (29\%) was found in 21 to 31 year of age. Hypertrophied Inferior Turbinate (HIT) 74 (39\%) and 54 (29\%) concha bullosa (CB) were associated with 188 septal deviation. Associated pathologies like maxillary sinusitis $82(44 \%)$ and maxillary antral cyst 78 (41\%) were documented.

Conclusion: CT scanning detects the abnormal anatomic variants and associated sinonasal pathologies along with nasal septal deviation. Endoscopic septoplasty, correction of the anatomical variants and complete surgical clearance of the sinonasal pathologies can give the patient a long term outcome.

\section{Introduction}

Nasal obstruction is the most frequent nasal symptom presented to the otorhinolaryngologist all over the world; and nasal septal deviation, its most frequent pathological correlate and the reason for septoplasty. The patients usually present with headache, postnasal rhinorrhea, facial pain, epistaxis, snoring, Obstructive Sleep Apnea (OSA), ophthalmological, 
otological, upper and lower respiratory tract infections for many years. CT reveals nasal septal deviation by measuring a distance from the midline above to the nasal floor [1].There are many other anatomical abnormalites of the structures in the nasal cavities responsible for nasal obstruction such as Hypertrophied Inferior Turbinate (HIT), Concha Bullosa (CB) and other pathologies in the paranasal sinuses may be associated with septal deviation namely Chronic Rhinosinusitis (CRS), nasal polyposis, mucocele, mucous retention cyst, tumors, and many more. Physical examination, Anterior Rhinoscopy (AR) and Nasal Endoscopy (NE) are considered the "gold standard" to evaluate septal deviation [2] and primarily used in the diagnosis of the nose and paranasal sinus diseases. These examination tools have definite limitations in finding the high and posterior deviations as well as the septal pneumatization which contribute for nasal obstruction. Septal deviation is usually associated with compensatory HIT and CB/ Paradoxical Middle Turbinate (PMT). The association of HIT or CB/PMT is not only caused by mucosal hypertrophy, but also by hypertrophy of the inferior and middle turbinate bone [3]. The contribution of preoperative CT scanning helps to detect those anatomical septal and turbinate variants; and.is of definite value in the evaluation of nose and paranasal sinus diseases for its subsequent and effective management [4], with a view to achieve a durable or permanent functional outcome. There is a debate in the use of CT in the septal surgery where the costs and radiation hazards of CT is used to be considered an initial additional burden [5]. In this study it has been shown that correction of other variants and pathologies along with septal surgery at the same sitting give rise to a long term benefit to the patients that prevent second surgery indeed. With the introduction of CBCT in the Head-neck region and in oral-maxillofacial/dentistry, the costs and harmful effects of radiation has reduced to a great extent [6].

The use of endoscope in septal surgery has significantly changed the concepts of septal surgery. The advent of nasal endoscope has revolutionized the diagnosis and treatment modalities of nose and paranasal sinus diseases and has widened the horizon of rhinology [7,8]. Lanza, et al. and H.Stammberger initially described the application of endoscopic technique for the correction of septal deformity in 1991 [9]. Nasal endoscope has the advantage to deal in complex deformities particularly high and posterior septal deviation resulting better septal correction and thus is gaining its popularity. Endoscope also aids in limited septal resection and removes ancillary sinonasal abnormalities thus more patient benefit is achieved $[10,11]$.

The aim of this study is to evaluate the contribution of preoperative Computed Tomography (CT) scanning in endoscopic septoplasty.

\section{Patients and methods}

The study included on 188 patients with nasal septal deviation in Bangladesh Medical College and Popular Medical College Specialized Hospitals from 2015 to 2019. Physical examination, anterior rhinoscopic and diagnostic nasal endoscopic examination were done in all patients after taking proper history in the ENT outpatient department. 188 patients presented with different types of septal deviation. Preoperative CT scanning both coronal, axial and sagittal view with $3 \mathrm{~mm}$ section was taken in all 188. Endoscopic septoplasty was done in all 188 patients under general anesthesia. The patient who needed ancillary procedures with endoscopic septoplasty was recorded. Their age ranged from 10 to 70 years; 126 males and 62 female respectively.

\section{Inclusion criteria}

$>$ A prospective, longitudinal, non-randomized study

$>$ Obtained informed consent from all patients prior to their inclusion in the study

$>$ Nasal septal deviation

$>$ CT scans of nose and paranasal sinuses with 3-mm cut in coronal, axial and sagittal plane with bone window settings.

\section{Exclusion criteria}

$>$ Patients suffering from rhinosinusitis or nasal polyposis, granulomatous diseases of the nose, allergic rhinitis or nasal masses, or with a past history of nasal surgery.

\section{Results}

In this study most patients were 31 to 40 years old (35\%) and $29 \%$ were 21 to 31 years old (Table 1 ).

Among 168 patients, 69\% were male and 31\% were female (Table 2).

CT scanning was done in all 168, amongst them HIT $32 \%$, CB/PMT $29 \%$ and posterior deviation $14 \%$ shown in Tables $3-5$.

\begin{tabular}{|c|c|c|}
\hline Table 1: Age distribution. & \multicolumn{2}{|c|}{} \\
\hline Age in years & No of patients & $\%$ \\
\hline $10-20$ & 12 & 07 \\
$21-30$ & 54 & 29 \\
$31-40$ & 63 & 34 \\
$41-50$ & 26 & 15 \\
$51-60$ & 18 & 11 \\
$61-70$ & 06 & 04 \\
\hline
\end{tabular}

Table 2: Sex distribution.

\begin{tabular}{|c|c|c|}
\hline Sex & No of patients & $\%$ \\
\hline Male & 126 & 67 \\
Female & 62 & 33 \\
\hline
\end{tabular}

Table 3: CT finding - anatomical variants with septal deviation (no168).

\begin{tabular}{|c|c|c|}
\hline Anatomical variants & No of patients & $\%$ \\
\hline Hypertrophied inferior turbinate(HIT) & 74 & 39 \\
Concha bullosa (CB)/Paradoxical & & \\
middle turbinate (PMT) & 54 & 29 \\
High deviation & 08 & 05 \\
Posterior deviation & 24 & 14 \\
Septal pneumatization & 16 & 10 \\
\hline
\end{tabular}


Table 4: CT finding - associated sinonasal and other pathologies.

\begin{tabular}{|c|c|c|}
\hline Pathologies & No of patients & $\%$ \\
\hline Maxillary sinusitis & 82 & 44 \\
Frontal sinusitis & 24 & 14 \\
Maxillary cyst & 78 & 41 \\
Otitis media with effusion & 34 & 20 \\
Chronic otitis media & 45 & 27 \\
\hline
\end{tabular}

Table 5: Endoscopic septoplasty with other procedures.

\begin{tabular}{|c|c|c|}
\hline Procedures & No of patients & $\%$ \\
\hline Endoscopic septoplasty only & 72 & 43 \\
\hline Endoscopic septoplasty + Turbinoplasty & 54 & 32 \\
Endoscopic septoplasty +Conchplasty & 48 & 29 \\
Endoscopic septoplasty + FESS & 84 & 50 \\
Endoscopic septoplasty + Myringotomy & 34 & 20 \\
Endoscopic septoplasty + Tympanoplasty & 45 & 27 \\
\hline
\end{tabular}

\section{Discussion}

Nasal obstruction is the most frequent complaint in otolaryngology all over the world and a septoplasty is the common performed procedure. The use of endoscope in septal surgery has significantly changed the concepts of septal surgery. Patients usually reported with the complaints of headache, postnasal rhinorrhea, facial pain, snoring, Obstructive Sleep Apnea (OSA), otological and orbital symptoms, upper and lower respiratory tract manifestations many years. Physical examination with anterior rhinoscopy and nasal endoscopy was considered the gold standard for detecting septal deviation. Computed tomography (CT) can also be used to evaluate the deviated nasal septum, anatomical variants of the other nasal components and unveils the associated sinonasal diseases [1214]. The basic objective of endoscopic septoplasty is to alleviate the clinical manifestations caused by septal deviation and its effects; and to treat other ancillary pathologies.

The contribution of preoperative CT prior to endoscopic septoplasty proved definite benefit on functional outcome that has been highlighted in this study. Although its role in the deviated nasal septum is debatable; while some studies have shown that it is unnecessary for the diagnosis and management of deviated septum [5]. Another group of study opined that it significantly influences the surgical management. These studies showed different results and opinions observed in the literature review subjecting computed tomography, septal deviation and septoplasty. Although it has been aptly emphasized that CT is the "gold standard" in the diagnosis of sinonasal pathologies, opinion differs in the evaluation of septal deviation [5].

CT possesses costs and radiation hazards that would be an initial additional burden in septal surgery but the added advantages were correction of other variants and pathologies at the same sitting which give rise to a long term benefit that prevent second surgery. With the introduction of Cone-Beam Computerized Tomography (CBCT) in the Head-neck region and in oral-maxillofacial/dentistry, it becomes evident that the costs and harmful effects of radiation has been reduced to a great extent [6].

Hypertrophied inferior turbinate (39\%) was found in this small series, it become evident that the bony deformity along with the mucosal hypertrophy in the contralateral side of septal deviation which corresponds most of the published literature $[14,15]$. Preoperative CT was useful as a deciding factor to detect the septal deviation and nasal turbinates' in three dimensional views on the surgical technique of turbinate treatment with septoplasty.

Physical examination, anterior rhinoscopy and nasal endoscopy are the hall mark to discover most of the nasal pathologies with certain limitation in the finding of CB/PMT in its entire length and extension of the mucous hypertrophy and bony overgrowth which was clearly evident on coronal and axial CT [16]. The mucosal and bony structures of the middle turbinate and the angle of the septum were assessed using radiological analysis before septoplasty to have good result that was documented in this study.

Over the years, the attention for OSA is growing around the globe and nasal septal deviation is one major cause. It is only responsible when it is markedly deviated what can be easily found in the conventional otolaryngological examination.

A high deviation is very difficult to recognize and was the responsible factor for nasal obstruction in 8 patients of our series, and evident in CT scanning. The high deviation of the septum also narrows the frontal recess resulting frontal sinusitis leading to headache [11]. Posterior deviation and septal penumatization are clearly revealed in computed tomography. Correction of the particular areas with septal surgery alleviated symptoms completely in this series.

Physical examination, AR and NE are practically unable to visualize the posterior areas of the nasal cavities in the grossly deviated nasal septum or septal spur. CT scanning is such a modalities of investigation which provide details to the otolaryngologists / radiologists that could not be seen on regular physical examination. Thus CT has the advantages to see the ostiomeatal complex with unveiling of the paranasal sinus condition $[17,18]$. In this series, maxillary sinusitis was found in 62 patients and showed significant other sinus diseases who needed septoplasty and functional endoscopic sinus surgery (FESS) with septoplasty. CT revealed maxillary antral cyst in 78 patients; very large cysts occupying $1 / 2$ to $2 / 3^{\text {rd }}$ of the maxillary sinus, underwent FESS. Small cysts did not require any surgical intervention. Out of 12 patients in the age group 10 to 20 years, 3 patients were below 15 years who had gross anterior septal deviation and severe nasal obstruction. They had associated adenoidal hypertrophy and required septoplasty with adenoidectomy.

The association of otitis media with nasal septal deviation has been found on CT scanning; and in our series otitis media with effusion and otitis media were ancillary findings. The patients had been treated septal correction and myringotomy with a remarkable result. Chronic otitis media was also given special attention with septoplasty. It has been explained that deviation of the nasal septum interferes Eustschian tube function that changes the middle ear pressure and affects pneumatization of the mastoid $[19,20]$. CT has the advantages to explore the mastoid, septum and nasopharynx [21,22]. 


\section{Conclusion}

The contribution of CT in the evaluation of nasal septum and its associated finding in the present study has a great impact prior to surgery; and it gives a long term functional outcome. CT possesses certain costs and radiation hazards but with the advent of CBCT in the head neck and oral maxillofacial surgery draws special attention to minimize costs at a very reasonable level and reduce radiation hazards to an extreme low to that of computed tomography.

\section{References}

1. Tomblinson CM, Cheng MR, Lal D, Hoxworth JM (2016) The Impact of Middle Turbinate Concha Bullosa on the Severity of Inferior Turbinate Hypertrophy in Patients with a Deviated Nasal Septum. AJNR Am J Neuroradiol 37: 13241330. Link: https://bit.ly/2Y380DO

2. Orhan I, Aydin S, Ormeci T, Yılmaz F (2014) A Radiological Analysis of Inferior Turbinate in Patients with Deviated Nasal Septum by Using Computed Tomography. Am J Rhinol Allergy 28: 68-72. Link: https://bit.ly/344Co5Y

3. Karatas D, Yüksel F, Sentürk M, Doğan M (2013) The Contribution of Computed Tomography to Nasal Septoplasty. J Craniofac Surg 24: 1549-1551. Link: https://bit.ly/2PRnlyQ

4. Lechuga L, Weidlich GA (2016) Cone Beam CT Vs Fan Beam CT: A Comparison of Image Quality and Dose Delivered Between Two Differing CT Imaging Modalities. Cureus 8: e778. Link: https://bit.ly/3iMQ0qv

5. Wotman M, Kacker A (2016) What Are the Indications for the Use of Computed Tomography Before Septoplasty? Laryngoscope 126: 1268-1270. Link: https://bit.ly/3aryEfV

6. Miracle AC, Mukherji SK (2009) Conebeam CT of the Head and Neck, Part 2: Clinical Applications. American Journal of Neuroradiology 30: 12851292. Link: https://bit.ly/2DNMm14

7. Manjunath R, Chitradurga SV (2013) Is Endoscopic Septoplasty really superior to Conventional Septoplasty? National journal of otolaryngology and head neck surgery 1 .

8. Freer 0 (1992) The correction of deflections of the nasal septum with a minimum of traumation. J American Medical Association 38: 636.

9. Stammberger $\mathrm{H}$, Valerie $\mathrm{JL}$ Anatomy of the nose and paranasal sinuses. $7^{\text {th }}$ edition, Scott Brown's otolaryngology and Head Neck Surgery 104: 1327.

10. Park DH, Kim TM, Han DG, Ahn KY (1998) Endoscopic-assisted correction of deviated nose. Aesthetic Plast Surg 22: 190-195. Link: https://bit.ly/3100hu6

11. Server EA, Karagoz Y, Çelebi OO, Yasak AG, Yigit O (2019) Impact of high septal deviation in the success of frontal sinus surgery. B-ENT 15: 319-324. Link: https://bit.ly/2Y4KeJ1

12. El-Anwar MW, Ali AH, Almolla RM, Monaem GA, Raafat A, et al. (2020) Radiological middle turbinate variations and their relation to nasal septum deviation in asymptomatic adult. Egyptian Journal of Radiology and Nuclear Medicine 51: 104. Link: https://bit.ly/3gZ5GXp

13. Poorey VK, Gupta N (2014) Endoscopic and Computed Tomographic Evaluation of Influence of Nasal Septal Deviation on Lateral Wall of Nose and Its Relation to Sinus Diseases. Indian J Otolaryngol Head Neck Surg 66: 330335. Link: https://bit.ly/31XL6Ag

14. Estomba CC, Schmitz TR, Echeverri CC, Reinoso FAB, Velasquez AO, et al.
(2015) Compensatory hypertrophy of the contralateral inferior turbinate in patients with unilateral nasal septal deviation. A computed tomography study. Otolaryngol Pol 69: 14-20. Link: https://bit.ly/30VNisW

15. Lebowitz RA, Suzanne K, Galli D, Holliday RA, Jacobs JB (2001) Nasal septal deviation: a comparison of clinical and radiological evaluation. Oper Tech Otolaryngol Head Neck Surg 12: 104-106.

16. Sedaghat AR, Kieff DA, Bergmark RW, Cunnane ME, Busaba NY (2015) Radiographic evaluation of nasal septal deviation from computed tomography correlates poorly with physical exam findings. Int Forum Allergy Rhinol 5: 258262. Link: https://bit.ly/2Y4JTWL

17. Lee DC, Shin JH, Kim SW, Kim SW, Kim BG, et al. (2013) Anatomical analysis of nasal obstruction; nasal cavity of patients complaining of stuff nose. Laryngoscope 123: 1381-1384. Link: https://bit.ly/2FuALo9

18. Gunbey E, unbey HP, Uygun S, Karabulut $H$, Cingi C (2015) Is preoperative $€$ paranasal sinus computed tomography necessary for every patient undergoing septoplasty? Int Forum Allergy Rhinol 5: 839-845. Link: https://bit.ly/2CrAkcO

19. Sistani SS, Dashipour A, Jafari L, Ghahderijani BH (2019)'The Possible Associations of Nasal Septal Deviation with Mastoid Pneumatization and Chronic Otitis. Open Access Maced J Med Sci 7: 2452-2456. Link: https://bit.ly/2E8xpXe

20. Kapusuz Gencer Z, Ozkiriz M, Okur A, Karaoavus S, et al. (2013) The Possible Associations of Septal Deviation on Mastoid Pneumatization and Chronic Otitis. Otol Neurotol 34: 1052-1052. Link: https://bit.ly/2Y5kJaq

21. Doyle W (2007) The mastoid as a functional rate-limiter of middle ear pressure change. Int J Pediatr Otorhinolaryngol 71: 393-402. Link: https://bit.ly/3gXHB3i

22. Kumar SRP, Patel SV (2020) A prospective study of deviated nasal septum giving rise to other ENT pathologies. Int J Otorhinolaryngol Head Neck Surg 6: 303-310. Link: https://bit.ly/3atoewh

Discover a bigger Impact and Visibility of your article publication with

\section{Peertechz Publications}

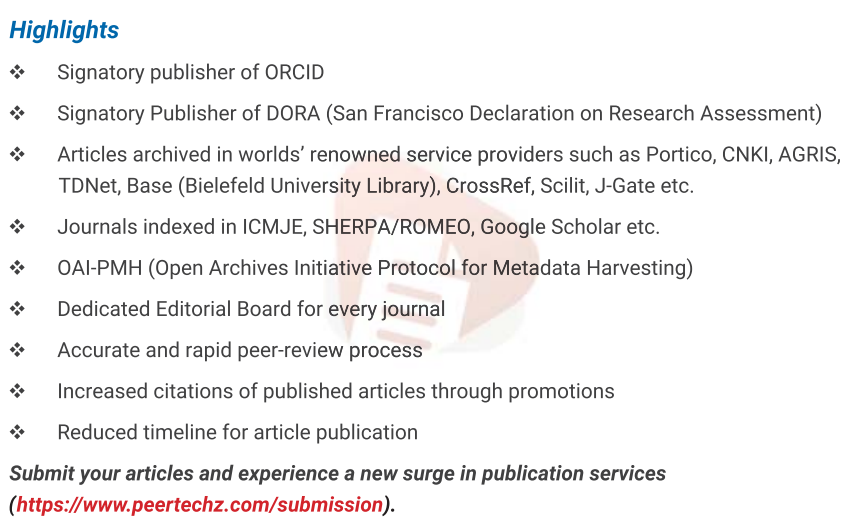

Peertechz journals wishes everlasting success in your every endeavours.

Copyright: ๑ 2020 Islam MA, et al. This is an open-access article distributed under the terms of the Creative Commons Attribution License, which permits unrestricted use, distribution, and reproduction in any medium, provided the original author and source are credited. 